\title{
TALK SHOW. Otro argumento para pensar la sociedad
}

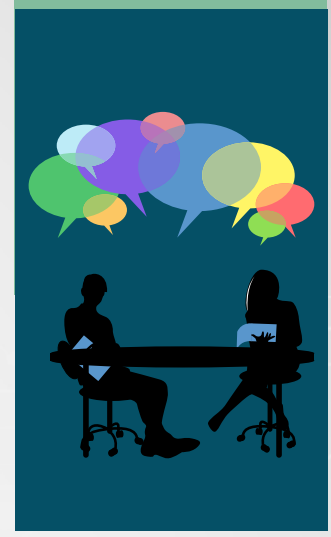

Leonardo Xavier Brito Alvarado *

Susana Paola Capito Álvarez **

Recibido: Agosto 30, 2016 - Aceptado: Septiembre 20, 2016

RESUMEN: El artículo hace referencia a la estrategia melodramática, las conversaciones y a la función que cumplen los invitados, el presentador y el público asistente a los talk shows. A partir de lecturas comunicacionales, antropológicas y sociológicas se pretende comprender estos programas más allá del anclaje del sin sentido comunicacional en los que se ha ubicado.

El estudio del talk show debe ampliarse hacia una ética mediática. Desde lo comunicacional, siempre habrá algo nuevo para contar sobre éste, su discurso es renovador, en el sentido antropológico por el enfrentamiento entre la cultura "élite" y "popular"; sociológicos por las disputas e imposición por los gustos. Problematizarles obliga a no verles como simples programas de espectáculo sobre la visibilización de la intimidad sino como argumentos para pensar a las sociedades.

Palabras clave: talk show, intimidad, melodrama, entretenimiento, visibilidad

\footnotetext{
* Máster en Antropología, FLACSO, sede Ecuador. Máster en Comunicación Universidad Andina Simón Bolívar, sede Ecuador. Licenciado en Comunicación Social, Universidad Central del Ecuador. Profesor titular de la Carrera de Comunicación Social, Universidad Técnica de Ambato, Ecuador. Email: Ix.brito@uta.edu.ec

** Magister en Educación, Universidad Tecnológica Equinoccial del Ecuador Quito. Licenciada en Educación Parvularia, Universidad Politécnica Salesiana. Maestra de Educación Inicial. Email: paocapito@gmail.com
} 


\section{TALK SHOW. Another argument for thinking it society}

SUMMARY: The article refers to the melodramatic, talks strategy and the role of the guests, the presenter and the audience to the talk shows. Starting from readings communicational, anthropological and sociological, is intended to understand these programs more beyond of the anchor of the without sense communication in which is has located.

The study of the talk show needs to expand into a media ethics. From communication, there will always be something new to tell about it, his speech is refreshing, in the anthropological sense by the conflict between the "elite" and "popular"; sociological disputes and imposition by the likes. Problematizarles forces do not see them as simple programs show about the visibility of privacy, but as arguments to think societies.

Key words: talk show, melodrama, intimacy, visibility, entertainment.

\section{TALK SHOWS.}

\section{Outro argumento para pensar a sociedade}

RESUMO: O artigo faz referência à estratégia melodramática, as conversações e a função que os convidados cumprem, o apresentador e o público participante no Talk Shows. A partir de leituras comunicacionais, antropológicas e sociológicas, pretende-se entender estes programas além do ancoradouro do sem sentido em que ficou situado.

O estudo do Talk Shows deveria ser aumentado para uma ética mediática. Desde o comunicacional, sempre haverá algo novo que contar sobre ele, a sua palestra é renovadora, no senso antropológico para a confrontação entre a cultura "élite" e "popular"; sociológicos pelas disputas e imposição pelos gostos. Problematizar-lhes força a não os ver como programas de espetáculos simples na visilidade da intimidade, senão como argumentos para pensar às sociedades.

Palavras chaves: talk show, intimidade, melodrama, entretenimento, visibilidade. 
Introducción

os productos mediáticos son algunos de los fenómenos que caracteriza al mundo contemporáneo. En estos la exposición de la intimidad se ha convertido en mercadería. Para John B. Thompson:

El desarrollo de los nuevos medios de comunicación ha dado lugar a un nuevo tipo de publicidad independiente del espacio que permite una forma de presentación personal muy íntima y liberada de las constricciones impuestas por la copresencia o comparecencia, estas son las condiciones que facilitan el auge de lo que podriamos llamar "la sociedad de la autorrevelación" (2001: 66).

La vida íntima está asociada a la idea propuesta por Anthony Giddens (2000), de una promesa de la democracia para que los sujetos puedan salir en los medios de comunicación y ser considerados como parte de una sociedad. La amplia variedad de productos mediáticos como "los libros de autoayuda, los talleres, los talk shows televisivos, los programas de radio con llamadas de los oyentes, las películas, las series de televisión, las novelas y las revistas han sido plataformas culturales esenciales para la difusión de la intimidad" (Illouz, 2008:18). La espectacularidad constituye la forma de narración imperante.

El talk show es una manera de dar fin a la intimidad por medio de conversaciones donde los participantes cuentan su vida (dramas) para un público deseoso de contemplar las tragedias ajenas. De ahí, que se caractericen como programas insertos dentro de la cultura "mainstream" como lo ha denunciado Martel (2012), destinados a la grandes masas de televidentes, dado que se centran en los tópicos de la cotidianidad, con un tratamiento mediático (televisivo) sensacionalista.

[...] los límites entre lo privado y lo público se difuminan fácilmente, ya que vivimos en un mundo en constante cambio, caracterizado por la falta de ideologías sólidas y por una revalorización de la cultura cotidiana. A ello contribuye en gran medida la exposición pública del ámbito privado generalmente en forma de espectáculo televisivo, especialmente a través de los "talk shows» y la "crónica rosa», géneros caracterizados por la trasgresión de los delicados límites entre los espacios privados, convencionales y morales.
La mercantilización de la intimidad no es algo exclusivo de los talk shows, desde inicios del siglo $\mathrm{XX}$ las industrias culturales la han abordado como un espacio económico antes que personal, para ello han construido una serie de narrativas, siguiendo a Illouz (2007), estas son: novelas y películas que se familiarizan como algo público. Han creado un nuevo código visual proveniente en su mayoría de la publicidad que introduce a la intimidad como un espectáculo, un código musical para crear un ambiente cercano con los otros; y un código lingüístico (prescriptivo) lejano y cercano a la vez.

Para Reguillo (2007), los talk shows son espacios mediatizados que explotan una negatividad social (modelos inadecuados) de la moral.

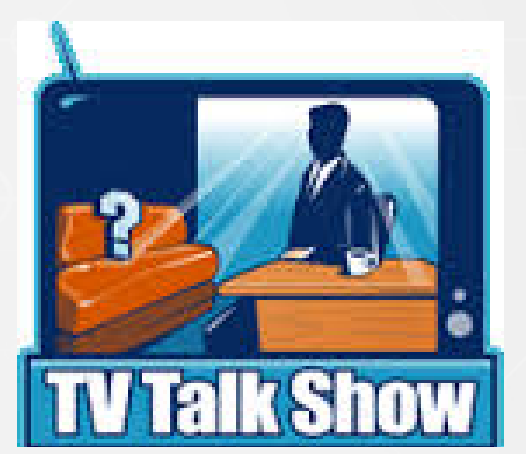

La intimidad "[...] no es un mero tema de la cultura contemporánea, sino que constituye un campo cultural en sí mismo, económicamente autónomo y con sus propios héroes, géneros, teorías y objetos" (Illouz, 2009:33). El talk show es una especie de espejo referencial donde se puede mirar y reconocer la gente como parte de un colectivo social y a la vez distanciarse de esto. La intimidad en este tipo de programas evoca a lo que Sigmund Freud denominó como 'escopofílico', es decir, "describir la pulsión erótica de la mirada del cuerpo del otro [...]" (Andacht, 2003: 13)

Los talk shows provocan una hiper visibilización que Gerad Imbert ha denominado como una "pornografía del sentir", categoría utilizada para describir el tratamiento mediático sobre las formas del sentir contemporáneo, una negativa como dolor, muerte y otra positiva como el amor, etc. Estos tipos del sentir evocan una violencia simbólica representada por la visibilización de la intimidad. Por tanto, "funcionan como espejo deformante de lo social, traduce una tendencia a la exageración, la extravagancia, el detalle insólito, la manifestación aberrante [...] expresa una fascinación por el desorden" (Escudero, 2005:16).

Siguiendo a Perniola (2003), la hipervisiblización de 
la intimidad se percibe como algo ya sentido, algo propio, una especie de espejo en el que se miran los sujetos, que da cabida a la espectacularidad sensitiva, convirtiendo al talk show como un doble sentir, de las emociones psicológicas y las representaciones culturales. Para Illouz (2003), el éxito de los talk shows radica en que han ocupado el espacio político gracias a las crisis de la moralidad, las creencias y los sistemas de valores personales que dominan las esferas públicas y las privadas de la vida.

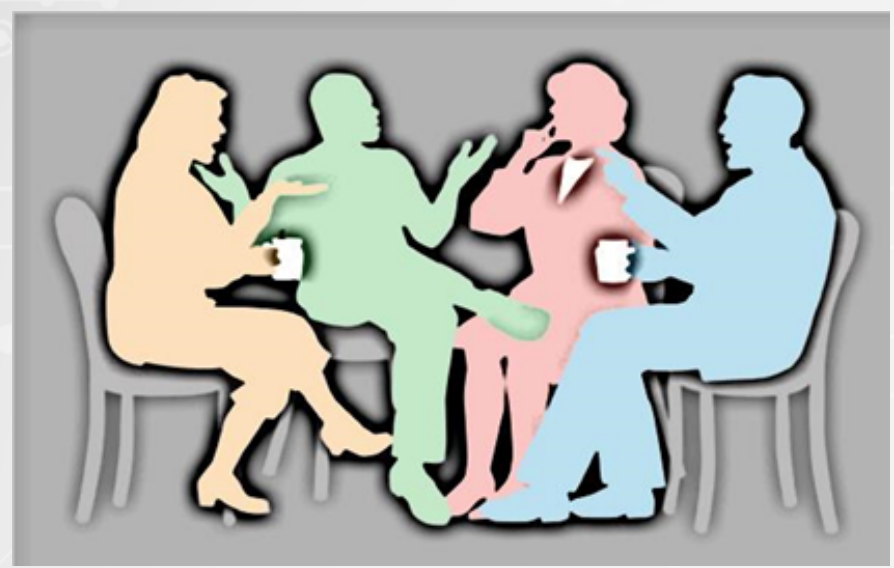

1. La estrategia melodramática del talk show

La pregunta que circula sobre los talk shows es ¿Constituyen una realidad dramática o una mentira basada en la espectacularidad? Estos programas conducen a una rutina televisiva en el sentido de programación, pero espectacular al momento de contar las historias de las personas, cada vez más bizarras, inverosímiles que seducen al televidente con historias cercanas y destinadas a entretener

La producción de los talk shows pueden ser rastreados en los discursos melodramáticos que han servido para recrear unas narrativas y estéticas desde lo popular que se moldean en función de los requerimientos de la producción mediática. Por ello ganan espacio en la representatividad social, el exceso y derroche son dos características del melodrama constituyendo una oposición a las estéticas "limpias, educadas y refinadas" de la clase burguesa. "Juzgado como degradante por cualquier espíritu cultivado, ese exceso contiene, sin embargo, una victoria contra la represión, contra una determinada "economía" del orden, del ahorro y la retención” (Martín-Barbero, 1993: 127).

Para Carlos Monsiváis (2000), el melodrama ha tenido una fuerte influencia dentro de las industrias culturales latinoamericanas que ha permitido construir: a) un televidente pasivo, b) el conservadurismo como la moral a seguir, c) los gustos culturales de las élites nacionales como elementos a resaltar, d) la ciudad convertida en sinónimo de modernidad, e) la sumisión del tiempo libre a la televisión, f) el discurso melodramático como la nueva esfera pública, g) gracias a estos programas la globalización mediática se instaló en los hogares latinoamericanos.

Jesús Martín-Barbero (1997), describe que el melodrama en América Latina ayudó a que las masas se integren como parte de una sociedad mediante una "sintaxis audio-visual" que solo se pudo consolidar dentro de los espacios mediáticos como la radionovela, telenovela, novelas, los reality shows, los talk shows, entre otros; que se convierten en espacios mediáticos con alto poder narrativo y económico.

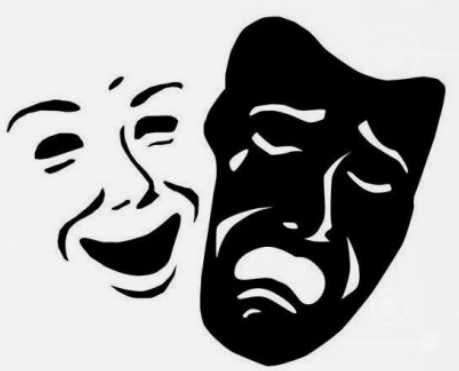

El melodrama, especialmente, en América Latina ha pretendido enfocarse en la búsqueda de una heterogeneidad narrativa que desborda el concepto de la modernidad europea por una local, permitiendo identificar las particularidades culturales de la región.

\footnotetext{
Este concepto iba ser celebrado por un creciente número de críticos como liberación del concepto de sus amarras impuestas por los administradores del "buen gusto". Desde entonces, la noción del melodrama ha vivido una serie de reconsideraciones que han abarcado, en los ámbitos de la academia occidental, los estudios de cine y más tarde de televisión, los estudios feministas, una parte de los estudios de la literatura y las artes dramáticas. (Herlinghaus, 2002: 24).
}

En este contexto, las imágenes, escrituras y miradas del talk show son asumidas desde un sentido melodramático de la cotidianidad, es decir, "se ofrece por excelencia para repensar lo popular dentro de los conflictos de la modernidad" (Herlinghaus, 2002: 42). El melodrama se convierte en discurso político y social que ha sido fuente en la construcción de una matriz simbólica-social de reconocimiento del pueblo como sujetos de derechos y parte de una colectividad. Como lo señala Michaela Ott: 
Es evidente que el melodrama tiene que luchar con una doble problemática de aceptación. Por un lado, presenta figuras que luchan por el reconocimiento de su valor propio; por otro lado, articula una forma de expresión que busca reconocimiento a nivel del discurso teórico (2002:248).

Como valor cultural no es una mera representación social, sino que es una forma de expresión de todo el sistema social, que permite el encuentro entre "lo tradicional", "lo local" y "lo global". De ahí que, el melodrama televisivo es aquel programa que es trasmitido en episodios diarios o semanales, donde la puesta en escena de discursos dramáticos funciona para la seducción de las audiencias. A partir de estos presupuestos se puede argumentar que "dentro de la complejidad de unos procesos comunicativos, el melodrama funciona como producto de una concepción sentimental del mundo [...] (Colón, 2002: 143).

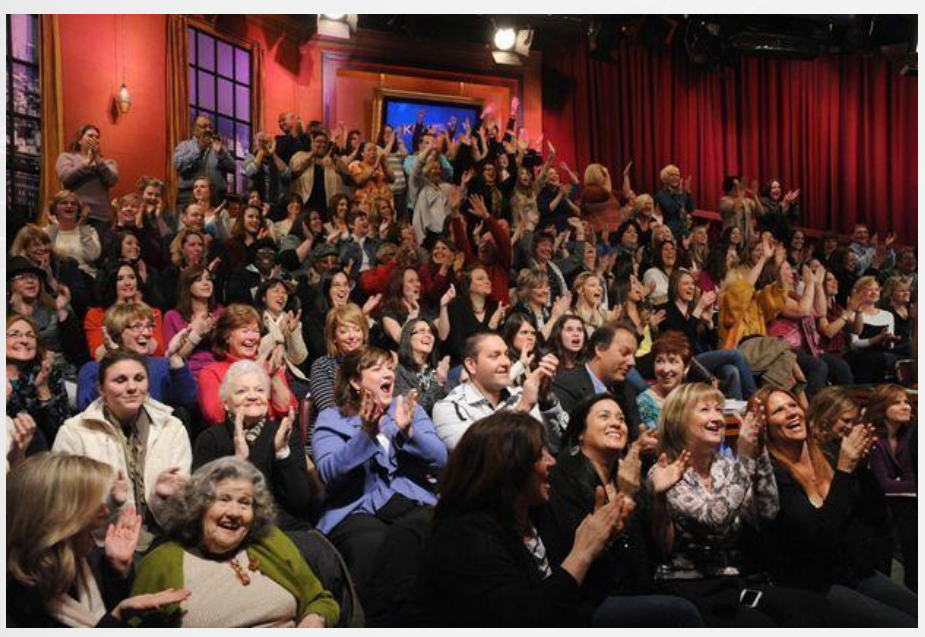

Para Francesco Casetti y Roger Odín, citados por Colón (2002:147), el talk show no pretende trasmitir conocimientos, ni saberes, su función es dar vía libre a las discusiones y confrontaciones cotidianas, un parloteo sobre la vida.

Estas producciones han tomado por asalto la intimidad de los sujetos convirtiéndola en un producto destinado a la recreación del público; la televisión ha visto a la intimidad como el recurso para el espectáculo masivo al convertirse en un espacio sociocultural, narrativo y estético, definiendo un sentido de proximidad social.

Estos han sido uno de los puentes para crear escenarios mediáticos de cercanía con la gente, haciéndola sentir parte de una sociedad cada vez más individualista y voyerista, este último concepto busca satisfacer la libido no por medio de la observación genital o imágenes pornográficas, sino por las historias de la intimidad. Estas pueden ser encasillas como la confesión por parte de los participantes ante una autoridad, en tal sentido, "al lado de los rituales consistentes en pasar por pruebas, al lado de las garantías dadas por la autoridad de la tradición, al lado de los testimonios, [...] la confesión se convirtió, en Occidente, en una de las técnicas más altamente valoradas para producir lo verdadero" (Foucault, 2006:35).

Los talk shows se construyen bajo una narrativa melodramática donde la relación se establece entre la promoción y autoventa de los participantes, y un público dispuesto a escuchar y deleitarse con los dramas. El mercado televisivo ha encontrado en estos programas un efectivo gancho para ganar audiencias ofreciendo entre otras cosas: goces, tensiones, inquietudes, emociones y alegrías. Estos programas son destinados a entretener y no educar; sin embargo, también implican una mirada política, económica e incluso ética de la sociedad, un modo de autorreconocimiento social.

El éxito radica, como lo explica Rossana Reguillo (2007), en que pone en escena los diversos conflictos de una modernidad periférica, ocultada por las "historias oficiales", de aquellos que han sido olvidados por las elites locales. En estos se puede describir desde una lógica de entretenimiento, una forma de vida, un objetivo en sí mismo que se desplaza y se inserta en la cotidianidad, creando una esfera de la representación de la realidad. Como lo menciona Rosario Lacalle (2000), el talk show ha podido asumir un discurso propio que lo diferencian de otros programas como los de glamour que se enfocan en la prensa rosa (vida de famosos), la vida de los actores políticos (noticias) o los programas para soñar (concursos), esto ha permitido dar cabida a la gente común, a la de la calle que representan, en cierta medida, los rostros la violencia, de felicidad, de la solidaridad y del esfuerzo por vivir. Esto ha convertido a los talk shows como los herederos del espectáculo del sollozo (sob show) de la televisión estadounidense de los años sesenta.

Estos programas en cierta medida son una máquina de producir espectáculos, crean narrativas de seducción, conformidad, afectos, que funcionan como la gran promesa mediática, "Ilevarnos fuera de nuestros problemas diarios, de escapar de la miserias de la vida" (Gabler, 1998: 45). Es por eso que son: 
Un complejo y sutil juego de intercambios $y$ retiradas, de aperturas y cierres, de silencios $y$ explicitaciones, $y$ se presentan como una combinatoria (de variables múltiples), de 'comunicaciones' cualitativamente heterogéneas, diversamente estratificadas $y$ mutuamente compensatorias. (De Certeau, 1995:140)

Para Rossana Reguillo (2002), los talk shows en América Latina constituyen una garantía y un espacio fértil para experimentar las hablas populares dentro de las tecnologías audiovisuales. Beatriz Sarlo (2014), los describe como la novela semanal que conecta al pueblo en historias en que la autorepresentación se hace evidente,

“ en la actualidad, hasta los programas de discusión política más reflexivos llevan público, reciben llamados telefónicos y sientan a la mesa a no expertos precisamente en su calidad de no expertos" (Sarlo, 2014:81-82).

La conceptualización del talk show se encuadra en una serie de emisiones dentro de una conversación/ discusión que giran sobre problemas particulares de la cotidianidad, especialmente de la familia, y el abordaje utilizado se basa en una espectacularización de las acciones de los sujetos involucrados, los actos testimoniales y la multiplicidad de voces (presentador, público y especialistas). Para Imbert estos son programas destinados, en su mayoría, para las mujeres ubicándolas en el centro de la narrativa melodramática y del consumo mediático; este formato televisivo saca a relucir situaciones familiares cercanas al entramado doméstico de la mujer.

Estos programas constituyen espacios en que se consagra la infelicidad de la sociedad, un lugar reservado a temas tabús: sexuales, maltratos, fetichismos; las víctimas, en su mayoría, de los casos son mujeres, homosexuales, incluso niños. También es un espacio simbólico de mediatización para que los grupos vulnerables hablen de sus desdichas. Vida privada en público, comunicación basada en la conversación, morbo en la mirada masiva. Los participantes son invitados cada día a lavar sus culpas y neurosis en público para aprender enseñanzas de su experiencia, siguiendo la lógica narrativa del formato llamado talk show o conversación pública a partir de la vida privada (Rincón, 1998: 26).

Para Monsiváis, los talk shows representan el marco teórico para un reconocimiento identitario latinoamericano que forman unas matrices estético/ expresivas que usan los medios de comunicación como plataforma de consolidación cultural.
El talk show se convierte en la continuidad de la matriz estética del melodrama. Algunos títulos de los programas más 'polémicos' que han circulado por América Latina, tal vez ayuden a ilustrar esta afirmación: 'mi esposo me engañó con la criada'; 'atrapado entre dos amores'; 'necesito un órgano para vivir'; 'soy borracho, parrandero y jugador'; [...] Cada uno de estos títulos -indicativos- instaura el conflicto básico que se abordará, es promesa de drama y no está alejados ni de los títulos ni de las tramas del melodrama cinematográfico en su época de oro (Reguillo, 2002:36)

Son una forma de contar la vida que se desplaza de la pantalla y se inserta en la cotidianidad del hogar, creando una serie de representaciones de la realidad. "El mundo del show y su emocionalidad actuada se ha multiplicado y ha llegado a donde jamás se creyó: la política, la religión [...] la vida se ha convertido en una actuación, una performance [...]" (Rincón, 2009: 58). Para Illouz (2003), estos programas funcionan como una clínica de manipulación de la condición de la miseria humana que se convierte en objeto mercantil mediático $\mathrm{y}$, por tanto, la intimidad es vendida a una audiencia deseosa del morbo. Este tipo de programas evoca conceptos de vigilancia y control social que constituyen narrativas televisivas contemporáneas destinadas a satisfacer el "apetito" lúdico-recreativo y voyerista de los espectadores.

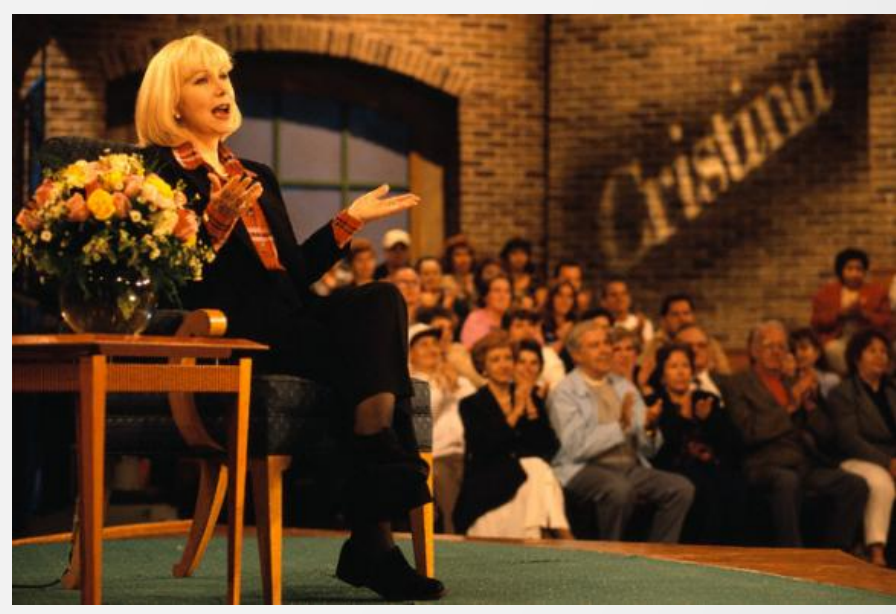

Para Jane Shattuc, retomada por Lacalle (2000), más allá de los consumos culturales y la ética social, los talk shows representan un importante aporte económico para los canales de televisión, que dio pasó a una competencia en la producción y distribución gracias al bajo coste de realización de estos programas. Imbert les ha caracterizado de la siguiente manera: 
a) Suele ser casi siempre de cuestiones sociales (mujeres maltratadas) o personales (mi marido me abandonó) [...].

b) Se requiere la participación del público y/o el espectador (mediante su presencia en el estudio o por teléfono).

c) Se estructura en torno a la "autoridad moral" de un conductor [...].

d) Su audiencia es mayoritariamente femenina [...].

e) Se emiten en franjas diurnas (mañana o tarde) (Imbert, 2003: 123).

En este sentido, y siguiendo a Guy Debord (2008), los talk shows son una acumulación de espectáculos imperando una lógica representacional de los sujetos y objetos (dramas).

\section{De actores, conversaciones y otras cosas}

Siguiendo la argumentación de July Chaneton (1998), los talk shows son una conversación audiovisual donde la circulación de relatos apasionados y violentos, se mezclan con juicios morales y consejos prácticos, confluyendo en un libreto, la exposición de la intimidad. Para conseguir este fin es necesario la presencia de tres personajes: conductora, por lo general mujer, encargada de llevar la dirección del programa poniendo sus reglas y personalidad mediática. Para Monsiváis (2002:122), ellas eligen los temas, aportan un sentido dramático y excesivo de las biografías de los participantes, su personalidad se impone ante todo, se apropia del programa.

Los presentadores o conductores de programas son un factor clave toda vez que, en ocasiones, su carisma, personalidad, "halo" o simplemente la simpatía de que gozan por parte de la audiencia hace que el programa suponga un éxito para la cadena. Estos profesionales (a veces actores, cantantes 0 simplemente personajes famosos) se han convertido en un valor añadido al programa (que incluso a veces proporciona el nombre a este (Cáceres, 1998: 280).
La función del presentador está determinada por ser la "voz autorizada" lleva para sí los primero planos de su rostro conduciendo a efectos de espectacularización los que para González (1998) constituyen una "escena no clausurada, (no) cerrada por límites precisos, sino abierta y constantemente móvil". Con el efecto de la ilustración se pretende que el presentador se convierta en una guía, un modelo a seguir por parte de los involucrados, dictaminando formas de comportarse en la sociedad. Este tipo de personajes se convierten en una especie de terapeutas. Para Illuoz (2007), el uso de narrativas psicológicas ayudan al abordaje de supuestas soluciones en el ámbito familiar, laboral, y así poder reingresarlos a una "normalidad" social, bajo la idea de una ideología del "lenguaje", la terapia se enfoca en la productividad, de ahí la necesidad de reingresar a las personas a un entorno "normal".

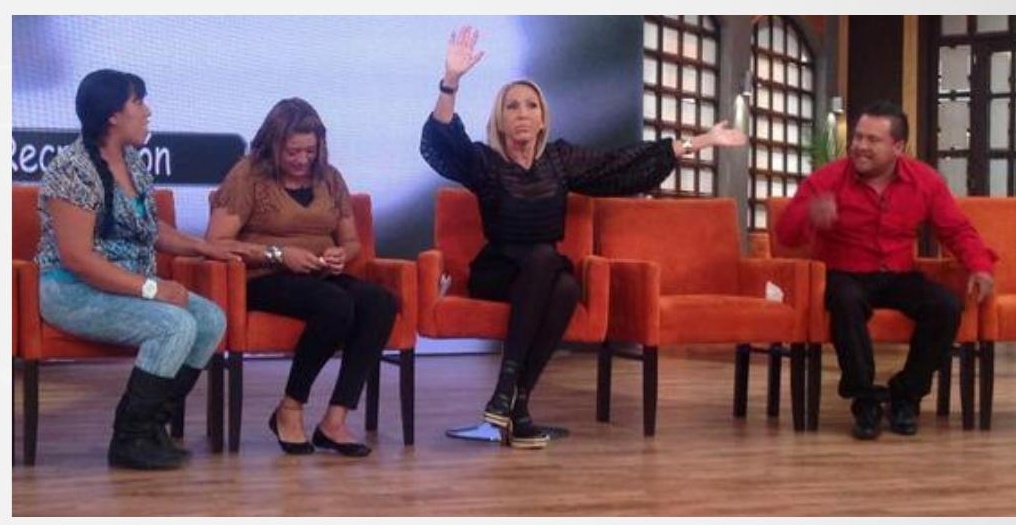

Los invitados juegan el segundo rol: se trata de hombres y mujeres, generalmente provenientes de clases económicas pobres que están frente a un espectáculo caracterizado por la conversación y la entrevista tipo policial. De acuerdo a Rincón (2003), los talk shows funcionan como un sistema psiquiátrico colectivo; donde el sentido del habla cercana al público es clave para su éxito comunicativo, que representan los deseos de la gente de la calle por salir en la televisión. Ellos actúan en busca de un reconocimiento social negado por el Estado, en la mayoría de los casos son los ausentes del diálogo político. En estos programas los invitados deslumbran sus virtudes, ejemplos de vida o reproches por su comportamiento, ellos

"[...] quieren que simpaticemos y nos identifiquemos con los héroes y las heroínas virtuosos/as, llenos/as de buenos intenciones y de gran generosidad, y quienes han tenido que enfrentar múltiples oprobios" (Colón, 2002:148). 
Para Gonzalo Abril (1995), los participantes poseen un vínculo emocional con los espectadores "él podría ser yo, yo podría ser él, todos somos cualquiera". La dramatización y la construcción de las historias son importantes para el desarrollo del programa y el "enfoque dramático", como lo plantea Goffman (2010), se pone en juego momentos para permitir la continuidad del show. Elaboran una construcción melodramática que se centran en diversos lenguajes del yo. Paula Sibilia (2008), describe esta relación como una especie de promoción y autoventa de los participantes.

Los participantes crean personalidades para ser dirigidas, que necesitan la aprobación del público para convertirse en una especie de celebridades, ovacionadas o repudiadas por las audiencias. Los espacios autobiográficos, señalados por Leonor Arfuch (2007), tendrían poco interés, sino tienen un nivel de empatía (simpatía y antipatía) con los espectadores, presentadores, público asistente y telespectadores, es importante para los personajes poseer determinadas características que pueden ser reconocibles de manera fácil por el público (madres solteras, infieles, pobres, hijos abandonados, entre otros), dado que en la cultura contemporánea la exaltación de lo vivencial ajena es asumida como una experiencia propia que funciona como una recuperación no solo de la mirada, sino en la construcción del sujeto social.

Lo vivencial debe ser trasparentado, no solo como una forma de entretenimiento, sino como una manera de sentirse parte de una sociedad. "Así, confesiones, autobiografías, memorias, diarios íntimos, correspondencias, trazarían, más allá de su valor literario intrínseco, un espacio de autorreflexión decisivo para el afianzamiento del individualismo como uno de los rasgos típicos de Occidente" (Arfuch, 2002: 33-34). En este espacio el sujeto se narra, el uso de la primera persona desempeña el centro del leguaje de referencia que sirve para la presentación al público. Los sujetos no se atañen a una sola autobiografía, sino diversas (padre, esposo, amante, hijo, trabajador, etc.), dada la necesidad de mostrarse multifacético y de sorprender en el escenario.

Lo vivido es siempre vivido por uno mismo, y forma parte de su significado el que pertenezca a la unidad de este 'uno mismo'. La reflexión autobiográfica o biográfica en la que se determina su contenido significativo queda fundida en el conjunto del movimiento total al que acompaña sin interrupción (Arfuch 2002, 35).
Estas autobiografías son maximizadas por un juego de cámaras, y por la utilización de planos que muestran rostros de dramatismo de los participantes con lo cual se busca construir una serie de percepciones sobre ellos para dar una impresión de verdad en sus relatos. La capacidad de interpretar el melodrama depende de los participantes, sus dotes actorales para hacer una presentación más cercana a la de un artista profesional, poniendo en juego, en ese momento, la continuidad de la presentación.

Los actores, de hecho, no tienen tiempo casi de estudiar los libretos; en la práctica les es imposible ensayar. Los actores más populares comienzan a interpretar un nuevo teleteatro, tan pronto como el anterior termina (Verón, 1993. 39).

El último rol lo constituyen el público que se divide en dos: los que asisten al set de televisión y los televidentes. Estos tipos de personajes tienen derecho a opinar e interrogar a los participantes $y$, como público receptor se identifican con el programa por el alto valor emocional que produce sus contenidos éticos y morales que, además, evocan un sentido de cercanía y familiaridad gracias a las historias y experiencias narradas. Siguiendo la línea de Goffman, el público en los talk shows actúa como investigadores que buscan saber la vida de los participantes.

\footnotetext{
Cuando un individuo llega a la presencia de otros, estos tratan por lo común de adquirir información acerca de él o de poner en juego la que ya poseen. Les interesará su status socioeconómico general, su concepto de sí mismo, la actitud que tiene hacia ellos, su competencia, su integridad, etc. (Goffman, 2010:3).
}

En cuanto a los temas de conversación Lacalle (2000), argumenta que los talk shows constituyen el ejemplo de la hibridez televisiva que ha ido poco a poco siendo parte de otros géneros televisivos, donde el amor y violencia son matrices discursivas. En este se conjuga una estructura de la conversación basándose en un debate de la vida privada que se desnuda frente al público y constituye uno de los formatos principales de la "neotelevisión", programas "concentrados televisivos". 
Para Sarlo (2014), el talk show permite articular características de la neotelevisión: ideario de que ésta puede solucionar los problemas que no han resuelto las instituciones públicas, la creación de un imaginario igualitario entre todos los que acuden, la sensación de registro directo. Claudia Laudano (1999), citando a Livingstone y Lunt, señala que estos escenarios se constituyen en espacios de mediación para intereses públicos vinculados de manera prioritaria a situaciones de crisis y carencias de los sujetos; espacios para ampliar el debate sobre las diversas problemáticas e iniquidades sociales, representan la dicotomía entre la visibilización de la miseria de la sociedad mezclada con un discurso moral, proporcionando una nueva oportunidad para aquellos que han cometido alguna falta. Para Illouz (2003), si bien representaría una explotación de la desgracia de una persona también la convierte en fuerte y triunfadora. En un contexto latinoamericano para Nora Mazzioti (2006), estos programas se presentan como una marca identitaria de lo latino, dado a que los problemas presentados evocan una generalidad regional, no existe una marca distintiva.

\section{CONCLUSIONES}

El estudio del talk show debe ampliarse hacia una ética mediática. Desde lo comunicacional, siempre habrá algo nuevo para contar sobre éste, su discurso es renovador, en el sentido antropológico por el enfrentamiento entre la cultura "élite" y "popular"; sociológicos por las disputas e imposición por los gustos. Problematizarles obliga a no verles como simples programas de espectáculo sobre la visibilización de la intimidad, sino como argumentos para pensar a las sociedades.

Las narrativas expuestas por los talks shows se enfocan en una dicotomía de emociones contradictorias, amar y odiar, mucho o poco ; ser débil o fuerte en una relación amorosa o familiar. Estos programas colocan a los sujetos y sus historias como productos de consumo mediático, sin embargo, en la narrativa buscan ayudar a sus problemas, es como si acudieran a una terapia psicológica colectiva.

El fundamento de la lógica narrativa de estos programas lo constituye mirada judeo-cristiana, los sujetos acuden a ventilar sus pecados ante una conductora y el público, en busca de ser perdonados por sus acciones; la recompensa el perdón. El performance actoral es clave para llegar a las audiencias, cada sujeto que interviene en el programa posee un rol específico: el bueno y el malo.
Lashistorias contadas son una construcción biográfica colectiva, se develan algunas características de las sociedades: violencia de género, machismo, infidelidad, abuso sexual, entre otras. Este tipo de programas puede estar circunscrito en la categoría propuesta por Erving Goffman de la dramaturgia, evidenciando que los individuos construyen una serie de actuaciones denominadas "performance" una teatralidad de su cotidianidad.

El vínculo entre esta categoría y los talk shows se da por: a) La definición de la situación, b) Elección de un escenario, c) audiencia y d) la representación. Estos aspectos son algunos de los identificatorios de los talk shows, que lo ubican para pensarlo como una interpretación de la sociedad. Es una historia con inicio, pero que carece de fin.

\section{BIBLIOGRAFÍA}

Abril, G. (1995). La televisión hiperrealista en Cuadernos de Información y Comunicación. No 1.Madrid. Universidad Complutense. Pp. 93- 101.

Aierbe, A. Medrano, C, Martínez, J. La privacidad en programas televisivos: percepción de los adolescentes. Revista Comunicar, vol. XVIII, núm. 35, 2010, pp. 95-103. Recuperado de: http://redalyc.uaemex.mx/src/inicio/ArtPdfRed. jsp?iCve=15815042012. Fecha de consulta: 18:08:2016.

Andacht, F. (2003). El reality show: una perspectiva analítica de la televisión. Bogotá. Editorial Norma.

Arfuch, L. (2002). "El espacio biográfico. Dilemas de la subjetividad contemporánea". Buenos Aires. Fondo de Cultura Económica.

Cáceres, M. La crónica rosa en "Televisión o el espectáculo de la intimidad". En Revistas de la Universidad Complutense: 24, 45-58. Recuperado de http://revistas.ucm.es/index.php/ClYC/article/ viewFile/CIYC0000110277A/7390

Fecha de consulta: 18:08:2016.

Chaneton, J. (2000). La vida ajena. Servicio, melodrama e intereses de género, "En los talk shows". Debate Feminista. México.

Certeau, De, M. (1996). "La invención de lo cotidiano, 1 Artes de hacer". Universidad Iberoamericana. México. 
Colón, E. Neotelivisión y melodrama. Las narrativas testimoniales. En H. Herlinghaus. En "Narraciones anacrónicas de la modernidad melodrama e intermedialidad en América Latina" (págs. 141-157). Cuarto Propio. Santiago de Chile, 2002.

Debord, G. (2008). La sociedad del espectáculo. La Marca Editora. Buenos Aires.

Escudero, L. (2005). Los formatos de la televisión. Gedisa. Barcelona.

Foucault, M. (2006). Historia de la sexualidad 1: La voluntad del saber. Siglo XXI, Buenos Aires.

García, L. (2009). Un análisis sociológico del reality show Gran Hermano 4 (Argentina). En Revista LIS, Literatura, imagen y sonido. Año 2 \# 4 . Facultad de Ciencias Sociales, Buenos Aires. UBA.

Gabler, N. (2000). Life the Movie. Vintage Books. New York.

Giddens, A. (2000). "La transformación de la intimidad. Sexualidad, amor y erotismo, en las sociedades modernas". Cátedra. Madrid.

Goffman, E. (2009). "La presentación de la persona en la vida cotidiana". Amorrortu editores. Buenos Aires.

Gubern, R. (2000). "El Eros Electrónico". Taurus. Madrid.

Herlinghaus, H. (2002). «La imaginación melodramática. Rasgos intermediales y heterogéneos.» En Narraciones anacrónicas de la modernidad, de Hermann Herlinghaus, (págs. 2160). Cuarto Propio. Santiago 2002.

Illouz, E. (2010). "La salvación del alma moderna". Katz Editores. Buenos Aires.

Illouz, E. (2003). Oprah Winfrey and the Glamour of Misery: An Essay on Popular Culture. Columbia University Press. Nueva York.

Imbert, G. (2009). “El zoo visual”. Gedisa. Barcelona.

Imbert, G. (2005) "La dilución de las fronteras: hacia una televisión sin fronteras". Gedisa. Barcelona,

Imbert, G. (1999). La hipervisibilidad televisiva: Nuevos imaginarios / nuevos rituales comunicativos. Madrid: "Textos de las I Jornadas sobre Televisión". Madrid. Universidad Complutense.
Lacalle, R. (2000). "Mitologías cotidianas y pequeños rituales televisivos". Los talk Shows: Revista Análisi 24. Barcelona. Págs. 79-82.

Laudano, C. (1999). Entre lo público y lo privado: la formulación de sus límites en el formato televisivo del talk show. Exhibición e invisibilidad de la violencia de género. . Recuperado de http://repositorio. flacsoandes.edu.ec/bitstream/10469/1484/1/ TFLACSO-1999CNL.pdf

Martel, F. (2012). Cultura Mainstream. Punto de Lectura. Madrid.

Martín-Babero, J. (2003). "De los medios a las mediaciones". Convenio Andrés Bello. Bogotá.

Martín-Babero, J. (1998). "Modernidades y destiempos latinoamericanos". Nómadas 7-19, Págs. 18-34.

Mazziotti, N. (2006), El show de Cristina y la construcción de lo latino. En G. Sunkel. El consumo cultural en América Latina: construcción teórica y líneas de investigación, (págs. 461-478). Bogotá. Convenio Andrés Bello.

Monsiváis, C. (2000). "Aires de familia. Cultura y sociedad en América Latina". Anagrama Editorial. Barcelona.

Monsiváis, C. (2002). El melodrama: "No te vayas, mi amor, que es inmoral llorar a solas. En $\mathrm{H}$. Herlinghaus, En "Narraciones anacrónicas de la modernidad melodrama e intermedialidad en América Latina" (págs. 105-123). Santiago de Chile: Cuarto Propio.

Monsiváis, C. "Lo entretenido y lo aburrido. La televisiónylastablas del rey". En Revista Universitaria. Recuperado:http://www.revistadelauniversidad. unam.mx/ojs_rum/files/journals/1/articles/13822/ public/13822-19220-1-PB.pdf

Ott, M. "El discurso melodramático. Entre cristianismos, psicoanálisis y cine". En $\mathrm{H}$. Herlinghaus, En Narraciones anacrónicas de la modernidad melodrama e intermedialidad en América Latina (págs. 245-281). Santiago de Chile: Cuarto Propio, 2002.

Perniola, M. (2012). La sociedad de los simulacros. Amorrortu editores. Buenos Aires. 
Reguillo, R. (2007). Formas del saber. Narrativas y poderes diferenciales en el paisaje neoliberal. En A. Grimson "Cultura y neoliberalismo" (págs. 91-110). CLACSO. Buenos Aires, 2007.

Reguillo, R. (2002). Épica contra melodrama. Relatos de Santos y Demonios en el "anacronismo» latinomaericano. En H. Herlinghaus, "Narraciones anacrónicas de la modernidad melodrama e intermedialidad en América Latina" (págs. 79-104). Cuarto Propio. Santiago de Chile, 2002.

Rincón, O. (2009). "Culturas mediáticas". Gedisa. Barcelona

Rincón, O. (2003). "Realitis. La narrativa total de la televisión". Revista Signo y Pensamiento. Págs.2236. Bogotá.

Sarlo, B. (2014). "Escenas de la vida posmoderna, Intelectuales, arte y videocultura en la Argentina". Siglo XXI, Buenos Aires.

Sibila, P. (2008) "La intimidad como espectáculo". Fondo de Cultura Económica. Buenos Aires.

Thompson, J. (2001). "El escándalo político: Poder y visibilidad en la era de los medios de comunicación". Paidós. Barcelona.

Verón, E. (1993). «Relato televisivo e imaginario social.» En N. Mazziotti. Tierra Baldía Buenos Aires.

\section{Para citar este artículo:}

Brito, A. Leonardo y Capito, A. Susana. (2016). Talk Show. Otro argumento para pensar la sociedad. Revista Luciérnaga/ Comunicación, Año 8, N16. Facultad de Comunicación Audiovisual- Politécnico Colombiano Jaime Isaza Cadavid-PCJIC \& Facultad de Ciencias de la Comunicación Universidad Autónoma de San Luis Potosí- UASLP. México. Págs. 48-58.

DOI. 10.33571/revistaluciernaga.v8n16a5 Link: http://www.politecnicojic.edu.co/images/downloads/ publicaciones/revista-luciernaga/luciernaga-14/ 